\title{
Tool condition monitoring of aluminum oxide grinding wheel using $A E$ and fuzzy model
}

\author{
Felipe Aparecido Alexandre ${ }^{1}$ (I) - Wenderson Nascimento Lopes ${ }^{1} \cdot$ Fábio R. Lofrano Dotto ${ }^{1} \cdot$ Fábio Isaac Ferreira ${ }^{1}$. \\ Paulo Roberto Aguiar ${ }^{1}$ - Eduardo Carlos Bianchi ${ }^{2}$. José Cláudio Lopes ${ }^{2}$
}

Received: 9 October 2017 / Accepted: 5 January 2018 / Published online: 17 January 2018

(C) Springer-Verlag London Ltd., part of Springer Nature 2018

\begin{abstract}
The grinding process is situated at the end of the machining chain, where geometric and dimensional characteristics and highquality surface are required. The constant use of cutting tool (grinding wheel) causes loss of its sharpness and clogging of the pores among the abrasive grains. In this context, the dressing operation is necessary to correct these and other problems related to its use in the process. Dressing is a reconditioning operation of the grinding wheel surface aiming at restoring the original condition and its efficiency. The objective of this study is to evaluate the surface regularity and dressing condition of the grinding wheel in the surface grinding process by means of digital signal processing of acoustic emission and fuzzy models. Tests were conducted by using synthetic diamond dressers in a surface grinding machine equipped with an aluminum oxide grinding wheel. The acoustic emission sensor was attached to the dresser holder. A frequency domain analysis was performed to choose the bands that best characterized the process. A frequency band of $25-40 \mathrm{kHz}$ was used to calculate the ratio of power (ROP) statistic, and the mean and standard deviation values of the ROP were inputted to the fuzzy system. The results indicate that the fuzzy model was highly effective in diagnosing the surface conditions of the grinding wheel.
\end{abstract}

Keywords Grinding $\cdot$ Dressing $\cdot$ Tool condition $\cdot$ Fuzzy $\cdot$ Monitoring $\cdot$ Acoustic emission

Paulo Roberto Aguiar

aguiarpr@feb.unesp.br

Felipe Aparecido Alexandre

felipe.alexandre@feb.unesp.br

Wenderson Nascimento Lopes

wendersonmanin@gmail.com

Fábio R. Lofrano Dotto

fabio@farolconsultoria.com.br

Fábio Isaac Ferreira

fab.kf@hotmail.com

Eduardo Carlos Bianchi

bianchi@feb.unesp.br

José Cláudio Lopes

jclaudio.lopes@homail.com

1 Department of Electrical Engineering, UNESP, Av. Eng. Luiz E. C. Coube, 14-01, Bauru, SP 17033-360, Brazil

2 Department of Mechanical Engineering, UNESP, Av. Eng. Luiz E. C. Coube, 14-01, Bauru, SP 17033-360, Brazil

\section{Introduction}

Manufacturing processes are of utmost importance due to the sharp increase in competitiveness among industries, tolerances of design increasingly tighter, increase in quality, and, especially, towards the manufacturing process optimization. The grinding process is often used for finishing the parts due to the ability to achieve geometrical characteristics and highquality areas with low surface roughness [1]. The grinding process is a cutting operation performed by using a grinding wheel, which contains randomly distributed abrasive particles. Thus, simultaneous distribution of the cutting edges as well as their undefined geometry results in a process with high stochastic behavior [2].

Dressing is the conditioning process of shape and sharpness of the cutting surface of the grinding wheel [3]. The topography of the grinding wheel influences directly on the surface roughness of the workpiece [4]. The constant use of the grinding wheel causes its wear and loss of the cutting capacity of the abrasive grains. In this context, it is necessary to perform the dressing operation, in which a diamond tool is used to remove a 
thin layer of material from the grinding wheel surface, aiming to remove the worn cutting edges and to produce sharp cutting edges [5].

Sharpness is a tool parameter that measures the ability of a body to remove material from another structure by virtue of its shape [6]. According to [7], the increase of the dressing depth entails an increase of the grinding wheel sharpness as well as a reduction of forces in the grinding process and rougher workpieces. Sharpness is important because it determines the capacity of the grinding wheel to remove material during the grinding process.

The monitoring of manufacturing processes helps with the failures detection during their operations. There are many methods for monitoring the condition of the dresser wear, such as acoustic emission (AE), vibration, and electric current. [8]. Among the advantages of using $\mathrm{AE}$ sensors are the ease of installation, monitoring without the need to interrupt the process, and the fact that the frequency range analyzed is higher than the machine vibrations and ambient noises [9].

Fuzzy logic has many applications in engineering where the domain of knowledge is usually imprecise. It is based on the theory of fuzzy sets, in which an association of objects in a set is continuous instead of just belonging or not belonging to the given set [10]. Fuzzy systems are close to the human reasoning sense.

The reason for obtaining information about the dressing operation is to improve the process, providing the operator the ability to schedule replacement of the dresser or the grinding wheel so that it is not too early or late to perform it, avoiding damages to the manufacturing. Thus, this article aims to evaluate the condition of the surface and shape of the grinding wheel through digital signal processing of acoustic emission and fuzzy models. Through studies on the frequency domain, selection of bands that best characterized the process, the use of digital filters, and, finally, application of the ratio of power (ROP) statistic in the acoustic emission signals, a vector of input data was obtained and then used in a fuzzy system. The results indicate that the fuzzy model was highly effective to provide information regarding shape and sharpening of the grinding wheel. This work stands out by studying the harmonic content of the AE signal applied to diagnose the shape and sharpness of the grinding wheel. A fuzzy system was used based on the ROP statistic, which was not applied in [11]. In [11], the raw signal was processed through statistical parameters and applied in neural networks, aiming the same purpose of the present work, that is, to diagnose the shape and sharpness of the grinding wheel during the process. Furthermore, the research work of [12] performed a study about the shape and sharpness of the grinding wheel by using the counts statistic and the harmonic content of the AE signal.

Thus, this work presents a unique approach through the application of ROP statistic along with a fuzzy controller and harmonic content study of the AE signal, aiming to detect the cutting surface condition of the aluminum oxide grinding wheel during the single-point dressing operation, that is, if the wheel has regular or irregular cutting surface and or if it is dressed or undressed.

\section{Monitoring the dressing operation}

The main goal of the grinding process is to ensure high quality to the finished workpiece. The growing field of automation in the manufacturing industry has been promoted by the need to maintain high product quality and increasing productivity [13].

According to [8], acoustic emission signal provides several types of information about the dressing process. However, more rigorous analyzes could be obtained from digital signal processing by using statistical parameters. Such parameters help to identify information which could be related to phenomena in the process. Among the statistical parameters that are applied in manufacturing processes monitoring with $\mathrm{AE}$ signals, the root mean square (RMS) parameter is the most common. Equation 1 defines RMS [8]:

$\mathrm{RMS}=\sqrt{\frac{1}{T} \int_{0}^{T} v^{2}(t) d t}$

where $T$ is the time constant integration and $v(t)$ is the instantaneous signal.

Over the last decade, several studies have been developed with the objective of measuring the dresser wear and proposing an optimized moment to replace the worn tools. A method for characterizing the condition of the dresser wear by using vibration signals and Artificial Neural Networks (ANN) was proposed by [14]. Tests were performed using single-point dresser in a surface grinding machine, and the wear was measured throughout the experiment. The results showed that the ANNs provide an effective method for monitoring the dresser wear.

In [15], a new approach in the dressing operation was proposed by using materials of high thermal conductivity (copper) on the dresser holder. Furthermore, cold air was projected into the contact between the dresser and the grinding wheel and thus getting rid of the coolant. Tests were performed to compare the difference of wear when using copper (high conductivity) and steel (conventional). The results showed that the diamond temperature was reduced by about $35 \%$, increasing the resistance to wear. The results were confirmed by scanning electron microscopy (SEM), 
measurements of energy consumption for different dressing conditions, and X-ray diffraction analysis. This new approach stands out for easy implementation and low cost.

The optimization of the dressing operation in cylindrical grinding (centerless) using load cells and applying the Tamaguchi method was presented in [16]. The input parameters were the dressing depth, the dresser feed rate, diameter of the grinding wheel and the wheel speed. The signal-to-noise ratio (SNR) was used for the selection of the best cutting conditions. The results showed that the dressing operation time was reduced, improving the process efficiency. Therefore, the Tamaguchi method allows for a better understanding of the dressing operation, concluding that the use of load cells for monitoring the dresser condition provides an extremely efficient diagnosis, besides helping in the grinding problems identification.

The monitoring of the dressing operation through AE signals and ANNs, with the goal of classifying the grinding wheel condition, was demonstrated in [11]. An aluminum oxide grinding wheel installed in a surface grinding machine, a data acquisition system, and a single-point dresser were used in the tests. The tests were performed by varying the overlap ratio and the dressing depths. The RMS and other statistical parameters were applied to the $\mathrm{AE}$ raw signals and input to a multilayer perceptron (MLP) ANN. The results indicated that this method was successful to classify the conditions of the grinding wheel in the dressing process, identifying the tool with cutting capacity or without cutting capacity.

The method proposed in [17] and adapted in [18] was used to measure the sharpness of the grinding wheel. This method consists of pressing a fixed disk (without rotation) against the grinding wheel with a constant normal force. Such disk is usually manufactured with the same material of the part to be ground. As the grinding wheel wears the disk out, the disk is displaced against the grinding wheel, and the displacement is acquired during a certain period of time. Subsequently, the regression and transformation are applied by the authors in [17], and the sharpness of the grinding wheel $(\mathrm{K})$ is determined by Eq. (2).

$K=\frac{2 b \sqrt{8 r}}{3 F_{N}} a^{\frac{2}{3}}$

where $b$ and $r$ are the width and radius of the disk, respectively, $F_{\mathrm{N}}$ is the normal force applied to the opposite end of the disk, and $a$ is the gradient of the regression line obtained from the characteristic curve of displacement versus $(t)^{2 / 3}$ or the characteristic curve of grinding wheel, where $t$ is the time of the experiment or contact time.

In [19], a comparison was performed between two types of ANNs with the aim at classifying the dresser wear condition, in which statistics applied to the AE raw signal were inputs to the neural models. Two ANNs of MLP type were compared regarding the ability of classification, one using RMS and the other using ROP, which is calculated by Eq. (3).

$\mathrm{ROP}=\frac{\sum_{k=n_{1}}^{n_{2}}\left|X_{k}\right|^{2}}{\sum_{k=0}^{N-1}\left|X_{k}\right|^{2}}$

where $N$ is the size of the AE data segment, $n_{1}$ and $n_{2}$ define the frequency range for analysis, and $X_{k}$ is the $k$ th output of the DFT. The value of $N$ equals to 2048 was used in this study. This statistic is dimensionless due to the power relation. It was found that both statistics have proven to be efficient, presenting an error of only $2.4 \%$, and therefore, the $\mathrm{AE}$ signal is influenced by the dressing tool condition.

The use of fuzzy models for wear prediction was presented in [20]. Vibration and AE signals were used as data sets for the fuzzy systems. The tests used synthetic diamond dressers in a surface grinding machine equipped with an aluminum oxide grinding wheel. Through a microscope, the dresser wear was measured every 20 passes. A study of frequency bands was conducted, and statistical parameters were applied to the signal. The results indicated that the fuzzy models proposed are highly effective in the process diagnosis.

In [12], a frequency domain analysis was performed on $\mathrm{AE}$ signals through the PSD with Welch's method, and frequency bands that best characterize the process were selected. After selecting the frequency bands, the counts statistic was applied with the objective of diagnosing the condition of shape and sharpness of the grinding wheel. The grinding wheel is one of the main tools responsible for quality of the grinding process. Its topography, shape, and sharpness affect directly on the surface quality of the workpieces [21]. The tests were performed in a surface grinding machine with aluminum oxide grinding wheel and the $\mathrm{AE}$ sensor was attached to the dresser holder. The results indicate that the statistics and the frequency bands that were selected are effective to determine the shape and sharpness conditions of the grinding wheel. Hence, this method could be used for the process automation.

The present paper differs from [11], because it first analyzes the harmonic characteristic content of the dressing process, associating such characteristics with different uniformity conditions of the grinding wheel, which was not considered in [11]. Furthermore, the present study has differences in relation to $[19,20]$ due to the fact that both are focused only on the condition of the dressing tool (dresser) using neural networks and fuzzy models, respectively, while this paper focuses on the condition of the cutting tool, i.e., the grinding wheel. Therefore, this work stands out for measuring, at the same time, the condition of the grinding wheel in terms of its shape and its sharpness, associating them with the characteristic frequencies of the 
dressing operation. Additionally, only one sensor is used, becoming the system simple to install and to execute the fuzzy controller.

\section{Fuzzy modeling}

The fuzzy logic (FL) is an analysis method purposefully designed to incorporate uncertainty into a decision model. In essence, the fuzzy logic allows for considering reasoning that is approximate rather than precise [22].

The fuzzy inference is the mapping formulating process from a given input to an output using fuzzy logic. The fuzzy inference process involves functions of association, fuzzy logical operators, and if-else rules. A membership function is a curve that defines how each point in the input space is mapped to a membership value, or degree of membership, between 0 and 1 [23].

The specialist of the fuzzy system can determine values of imprecision for the inputs at different levels. Therefore, it is common that different types of approaches are applied to better adapt to the degree of membership to each input. Some functions that could be applied are as follws: trapezoidal, linear, exponential, Gaussian, triangular, and even functions created by the user of the system [24].

According to [25], the implementation of fuzzy analysis can be divided in three main steps: Fuzzification of input values, reasoning based on rules, and defuzzification for the system output. According to [26], fuzzification is a process that sorts numeric values in fuzzy sets. The reasoning based on fuzzy rules is easily understandable to humans due to the linguistic terms associated with fuzzy sets [27]. Finally, the defuzzification is the process by which the fuzzy system returns a representative number of conditions analyzed as response, i.e., the response consists of a number belonging to a "crisp" set.

The approach through the fuzzy logic contains the potential to give a simplified control of applications in the field of engineering. The character based on rules of fuzzy model allows for an interpretation of the model in a way that is similar to the one humans use to describe the reality [28].

According to [29], there are two important aspects related to the control strategy in industrial applications of fuzzy control. In some situations, the fuzzy control has been suggested as an alternative approach to classical control (crisp) or conventional control. Compared to conventional control, the fuzzy control can be strongly based and focused on the human operator's experience. A fuzzy controller can model this experience with more accuracy in relation to the conventional control.

\section{Material and methods}

\subsection{Test bench and experiments}

The test bench was designed to analyze the surface conditions and shape of the grinding wheel from AE signals. To collect the signals, an oscilloscope DL850 model was used, from Yokogawa, at a sampling rate of $2 \mathrm{MHz}$.

The tests were performed for the dressing operation in a surface grinding machine, from Sulmecânica, RAPH 1055 model, which was equipped with an aluminum oxide grinding wheel, manufactured from NORTON, model 38A150LVH, with dimensions of $355.6 \times 25.4 \times 127 \mathrm{~mm}$.

A single-point dresser of synthetic CVD diamond (chemical vapor deposition) was used in the dressing tests, without using cutting fluid. Three dressing tests were performed with the aim of obtaining three conditions of shape and surface of the grinding wheel: dressed and even, dressed and uneven, and undressed and uneven. For the dressed and even condition, the dresser was considered in full contact with the surface of the grinding wheel. For the dressed and uneven condition, the dresser was in full contact with the surface of the grinding wheel only in a fraction of the dressing time. Finally, the undressed and uneven condition implies that grinding wheel is clogged (chips impregnated in the pores) and the dresser was in full contact with the surface of the grinding wheel only in a fraction of the dressing time. Before starting the tests, the grinding wheel was clogged and worn by using a piece of SAE 1020 steel in a grinding process, without cutting fluid, with wheel speed $\left(v_{\mathrm{s}}\right)$ of $33 \mathrm{~m} / \mathrm{s}$ and cutting speed $\left(v_{\mathrm{w}}\right)$ of $0.048 \mathrm{~m} / \mathrm{s}$. The dressing tests were performed with overlap ratio [11] of 1.5 and dressing depth of $10 \mu \mathrm{m}$. According to [30], the rough grinding is conducted when overlap ratio from 1.0 to 2.5 is used, i.e., any value belonging to this range could be chosen, and therefore, the value chosen for this study was of 1.5.

The dressing depth was determined based on preliminary tests, which indicated that the dressing configuration with the values mentioned previously best fit the proposed study. The phenomena related to phase and shape changes in the surface of the grinding wheel (undressed and uneven, dressed and uneven and dressed and even) occur more smoothly, allowing for a better observance of the phenomena by using acoustic emission signals. A higher dressing depth, however, hinders the observation of the dressed and uneven condition.

Table 1 shows the parameters of each dressing test, in which $v_{\mathrm{d}}$ is the dressing speed, $b_{\mathrm{d}}$ is the dresser width, and $t_{\mathrm{d}}$ is the dressing time.

The AE raw signal was obtained in real time by using an acoustic system, which consisted of a signal processing module, from Sensis, model DM-42, and the AE sensor from the same manufacturer, with frequency response up to $1 \mathrm{MHz}$, which is the same employed in [31]. Figure 1 shows the tests bench. 
Table 1 Test parameters

\begin{tabular}{lllllll}
\hline & Test $(n)$ & Pass & $v_{\mathrm{s}}(\mathrm{m} / \mathrm{s})$ & $v_{\mathrm{d}}(\mathrm{mm} / \mathrm{s})$ & $b_{\mathrm{d}}(\mu \mathrm{m})$ & $t_{\mathrm{d}}(\mathrm{s})$ \\
\hline Fuzzy system design & I & 10 & 33 & 9.8 & 520 & 2.6 \\
& II & 16 & 33 & 6.9 & 365 & 3.7 \\
& III & 24 & 33 & 9.8 & 520 & 2.6 \\
Validation & IV & 27 & 33 & 9.4 & 470 & 2.7 \\
& V & 13 & 33 & 9.4 & 470 & 2.7 \\
\hline
\end{tabular}

Visual inspections were performed during the tests by means of high-resolution pictures to assist in the identification of the grinding wheel conditions.

\subsection{Sharpness}

The displacement measurements of the grinding wheel against the disk were recorded by TESATRONIC, TT60 model, from Tesa Technology. Signals were collected via serial communication through Matlab software. The sharpness value of the grinding wheel was determined for different moments of the test; four curves of displacement over time were obtained for four positions along the cutting surface of the grinding wheel. Figure 2 shows the tests bench for the measurements of sharpness, which is constituted of the grinding wheel (a), sharpness measurement device (b), displacement sensor (c), samples (disks) (d), and TESATRONIC (e).

The cylindrical samples (disks) used in the acquisition process of the sharpness curves owned $24 \mathrm{~mm}$ external diameter, $7.8 \mathrm{~mm}$ internal diameter, and $2 \mathrm{~mm}$ thickness. These disks were made of SAE 1020 steel. The sharpness values were calculated using a force $F_{\mathrm{N}}$ of $1.02 \mathrm{~N}$.

To exemplify the behavior of the sharpness curve of the grinding wheel surface in function of time, the angles $\alpha$ and $\beta$ were computed to represent the wheel conditions, that is, undressed and uneven condition and dressed and even condition, respectively. The angles were obtained from the displacement curves versus time, from which the linear regression for the first ten samples were performed.

\subsection{Digital signal processing}

Initially, the AE raw signal was analyzed based on the period corresponding to the dressing time. Then, the signal was analyzed in the frequency domain with the objective of identifying frequency bands that best characterize the process behavior. The spectrum was obtained for three different conditions of the grinding wheel (undressed and uneven, dressed and uneven, dressed and even). The discrete Fourier transform (DFT) was obtained for nine equidistant points in the dressing pass. Therefore, nine vectors of 32.768 points were processed in Matlab by means of the fft command and Hanning window, and then the average of the spectra was calculated, representing the spectral behavior of the dressing pass. From the spectra analysis of these three conditions of the grinding wheel surface, a frequency band was selected using the nonoverlap criterion of the spectra, similar to the criterion used in the works of $[8,32]$.

To obtain the RMS values for each AE raw signal, the next steps were taken: Firstly, a Butterworth band-pass filter with

Fig. 1 Test bench

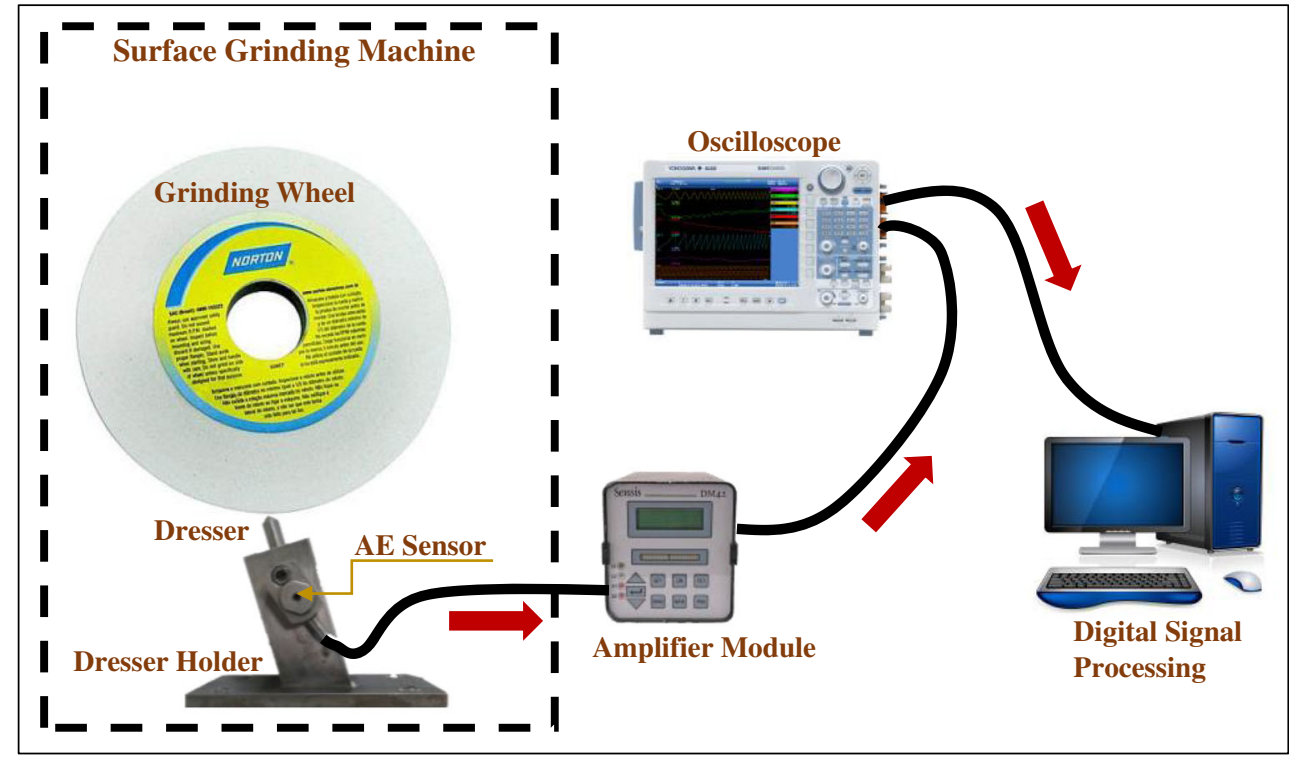


Fig. 2 Test bench for the sharpness measurements

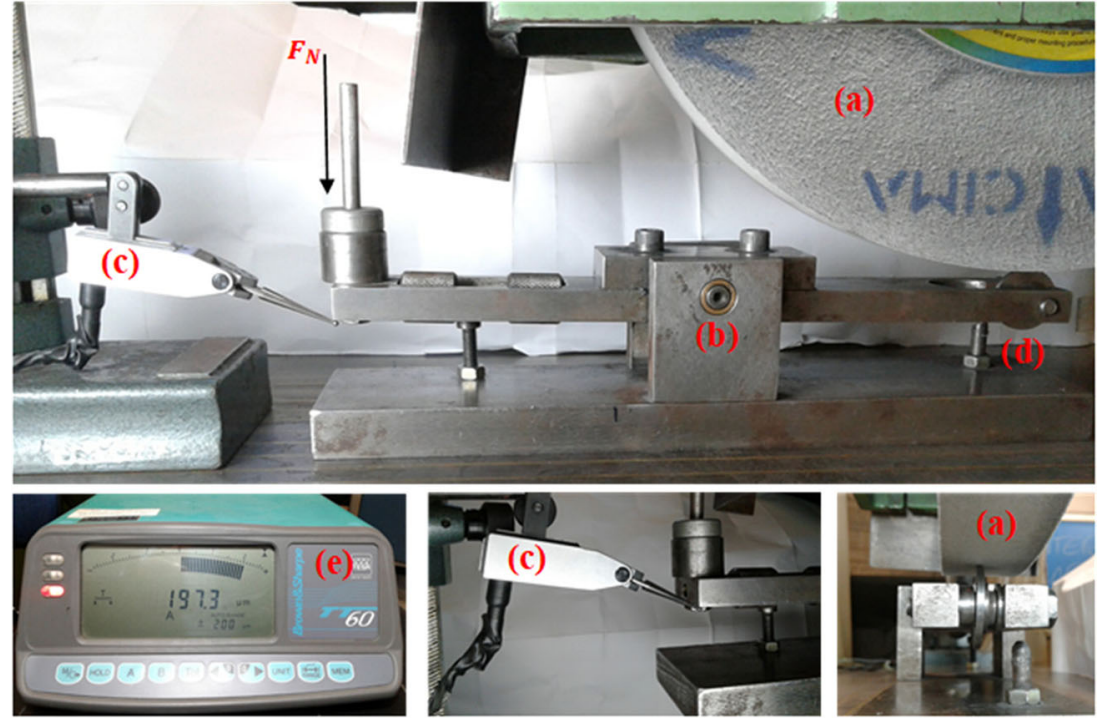

cutoff frequencies of $25-40 \mathrm{kHz}$ (frequency band selected from the spectra study) and of 30th order was implemented in Matlab to eliminate frequencies out of this range. Secondly, the dressing pass was extracted from the AE signal, that is, the range which refers to the contact between the cutting surface of the grinding wheel and the dresser diamond tip. Then, the RMS values were computed for each block of 2048 values of the extracted and filtered raw signal, which corresponds to $1 \mathrm{~ms}$, as suggested in [33]. Next, the signals obtained from the RMS calculation were filtered again, but using a Butterworth low-pass filter with cutoff frequency of $10 \mathrm{~Hz}$ and of first order. Thus, the mean RMS values and respective standard deviations were calculated for each dressing pass.

The ROP statistic of the pass-extracted raw AE signals (non-filtered) was computed based on the frequency band selected $(25-40 \mathrm{kHz})$ for each dressing pass. A window of $1 \mathrm{~ms}$, corresponding to 2048 points, was also used to calculate the ROP values along each dressing pass, as suggested in [33] to compute the RMS values. Finally, the mean values and standard deviations of the ROP statistic were computed for each pass.

\subsection{Fuzzy models}

The fuzzy models used in this study are based on the Mamdani method. The inputs to the system consist of the ROP mean values and ROP standard deviation of AE signals from the dressing process. The Gaussian type membership functions were used in the fuzzy system, due to smooth transition and better behavior in situations of sudden spikes, and they were generated by the gaussmf and gauss $2 m f$ commands in Matlab. The linguistic variables (low, medium and high) were used for both inputs. Regarding the system output, the following linguistic variables were adopted: undressed/uneven, dressed/uneven and dressed/even. The limits of the membership functions were determined by means of the analyzed dressing data of the passes and based on the experience of the research group in dressing operation. The centroid defuzzification method used in $[20,31,34]$ produced satisfactory results. Thus, this method was employed in the present study due to the same nature of the machining processes previously cited. Figure 3 presents the fuzzy system structure.

\section{Results and discussions}

\subsection{Visual inspection of the grinding wheel surface}

Figure 4 shows three different surface and shape conditions of the grinding wheel studied in this work, i.e., undressed and uneven (Fig. 4a), dressed and uneven (Fig. 4b), and dressed and even (Fig. 4c).

It is possible to identify grooves and several levels of clogging in Fig. 4a, exemplified and highlighted by three red circles. Such irregularities are related to the unevenness of the grinding wheel surface, which causes an uneven clogging. Based on the observation of Fig. 4c, the evenness condition is easily identified, because the surface of the grinding wheel presents no significant variations. On the other hand, the irregularities on the grinding wheel surface shown in Fig. $4 \mathrm{~b}$ are of difficult identification if this figure is alone analyzed, and therefore, other tools are required for such analysis, for instance the ROP statistic.

Thus, the Sect. 5.2 will discuss the results regarding the spectra of the raw AE as well as the criterion of frequency band selection based on the cutting surface conditions of the grinding wheel. On the other hand, Sect. 5.4 will present the discussion of the RMS and ROP results for the frequency band selected. 
Fig. 3 Diagram of the fuzzy system structure

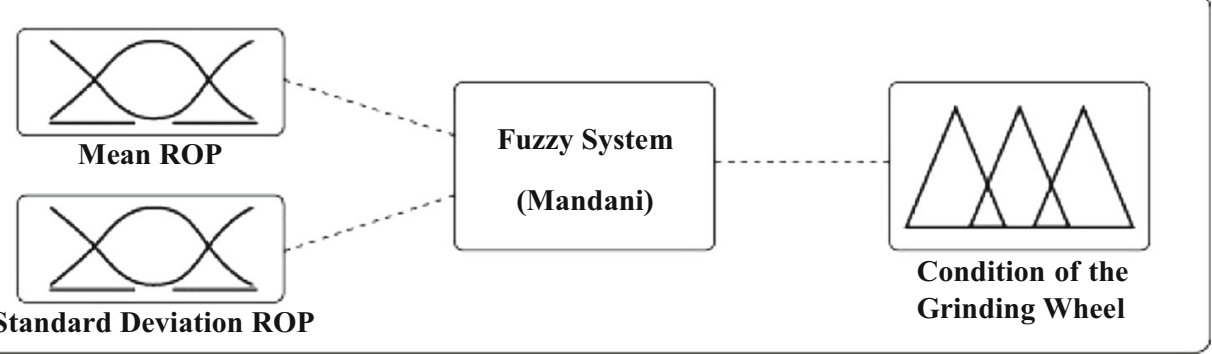

\subsection{Digital signals processing}

Figure 5a shows the frequency spectra from the raw AE signals for three different grinding wheel conditions. It is noticed that the most significant harmonic content for this study is between 20 and $80 \mathrm{kHz}$, with some peaks spread between 100 and $200 \mathrm{kHz}$. Figure $5 \mathrm{~b}$ shows a magnification of the frequency spectra in the selected band from 25 to $40 \mathrm{kHz}$.

The range chosen in Fig. 5b shows a few overlaps among the presented conditions. It is observed that the frequency spectrum has lower amplitudes for the undressed and uneven condition of the grinding wheels. This occurs due to the excessive wear on the grinding wheel surface (clogging) and its unevenness. According to [11], when the grinding wheel is clogged, there is not only a lower level of friction, but also less impact of the dresser with the grinding wheel. The chips impregnated in the grinding wheel act as acoustic damper. The dressed and even condition, illustrated in Fig. 5b, has a higher amplitude in the spectrum than the others. In this case, there is a full contact between the dresser and the grinding wheel, and consequently, the friction is large, resulting in an increasing acoustic activity. The intermediary condition (dressed and uneven) has different amplitudes due to the same reasons exposed above, i.e., the larger the contact area between the abrasive grains and the grinding wheel, the greater the amplitude of the signal and its spectrum.

\subsection{Sharpness analysis}

Figure 6a shows two sharpness curves for two different conditions: undressed and uneven and dressed and even. The shaded region identifies the curves used to calculate the sharpness of the grinding wheel. It should be noted that the greater the angle ( $\alpha$ and $\beta$ ) between the sharpness curve and the time
Fig. 4 Three different grinding wheel conditions. a Undressed and uneven. b Dressed and uneven. c Dressed and even

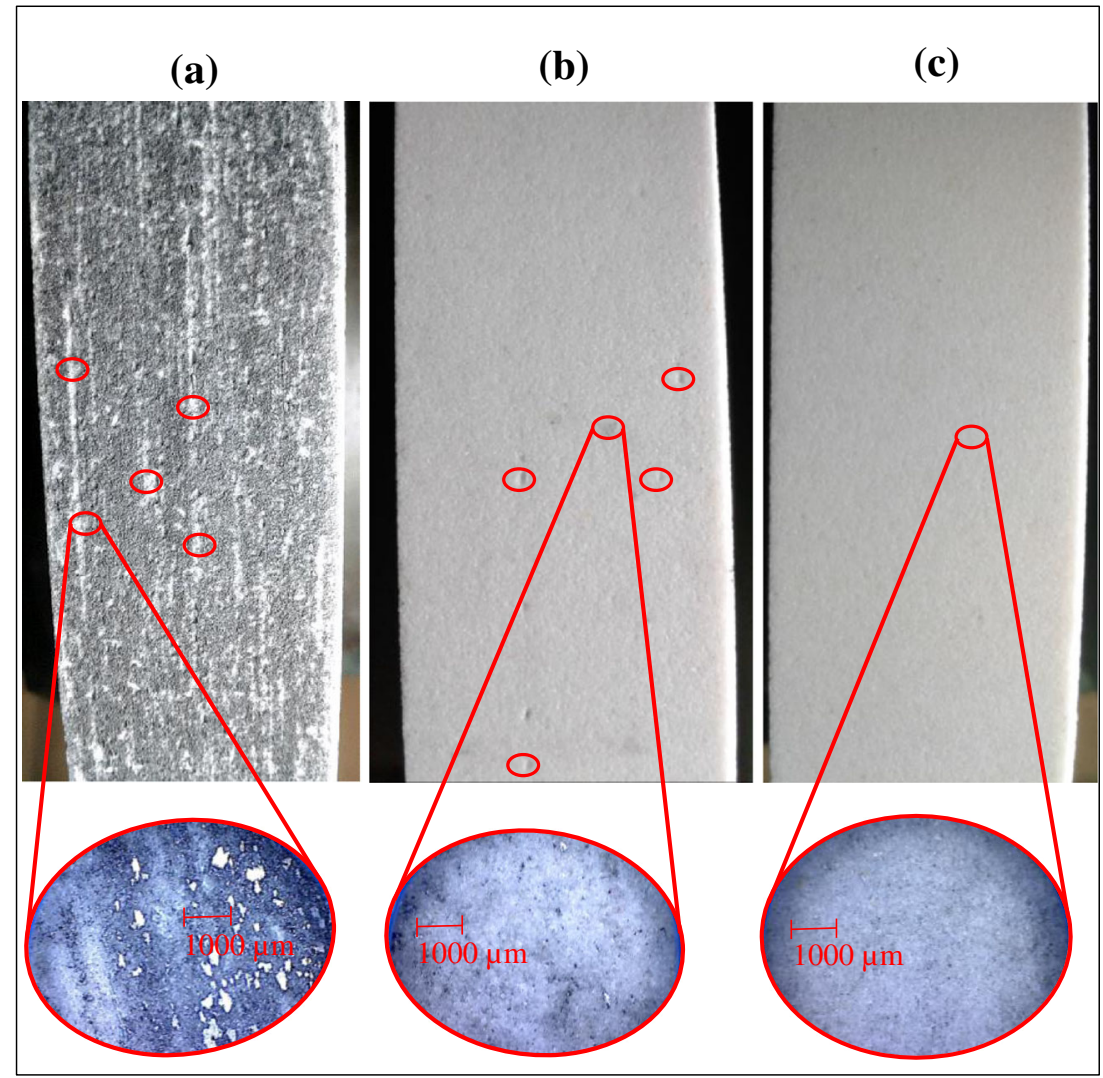


Fig. 5 a Spectra of the three grinding wheel conditions. b Magnification of the frequency spectra in the band from 25 to 40 $\mathrm{kHz}$

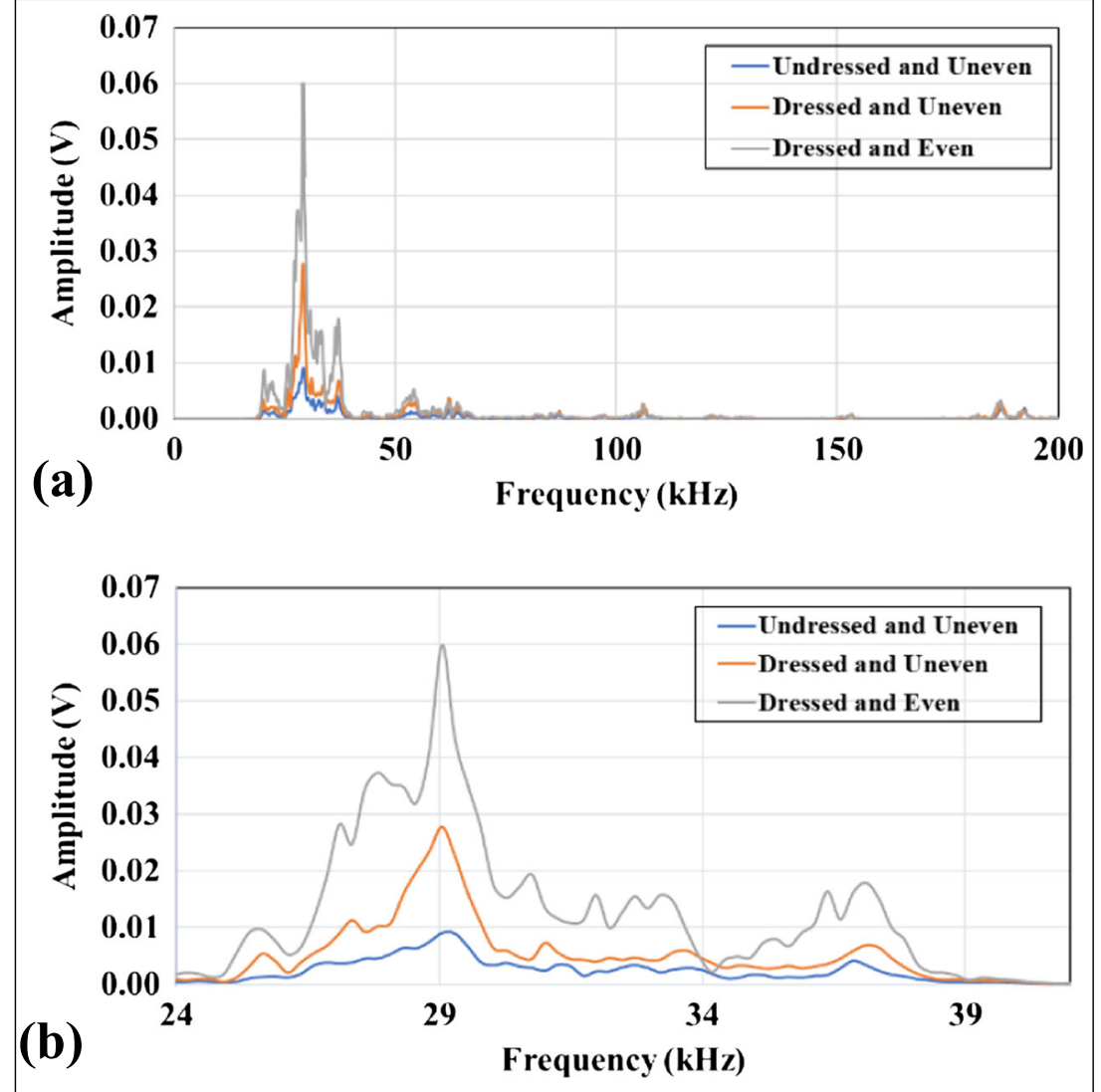

axis (that is, the more inclined the curve), the greater the sharpness of the grinding wheel.

Figure $6 \mathrm{~b}$ shows the magnification of the region used to calculate the sharpness. The curve corresponding to the undressed and uneven condition presents a low value for the $\alpha$ angle, which implies in a grinding wheel with low sharpness level. The grinding wheel in such situation has its abrasive grains with rounded shapes. This can occur due to the clogging or even to the natural wear of the grains. In contrast, the curve corresponding to a dressed and even condition shows an inverse situation, i.e., the $\beta$ angle between the sharpness curve and the time axis owns high value, indicating a sharp grinding wheel. Thus, in this case, the cutting edges are uneven and sharp and the abrasive grains are more protruding on the surface of the sharp grinding wheel.

Table 2 shows the angles ( $\alpha$ and $\beta$ ), the curves gradient $(a)$, and the sharpness values $(\mathrm{K})$ for two different conditions of the grinding wheel. It is observed that for a grinding wheel
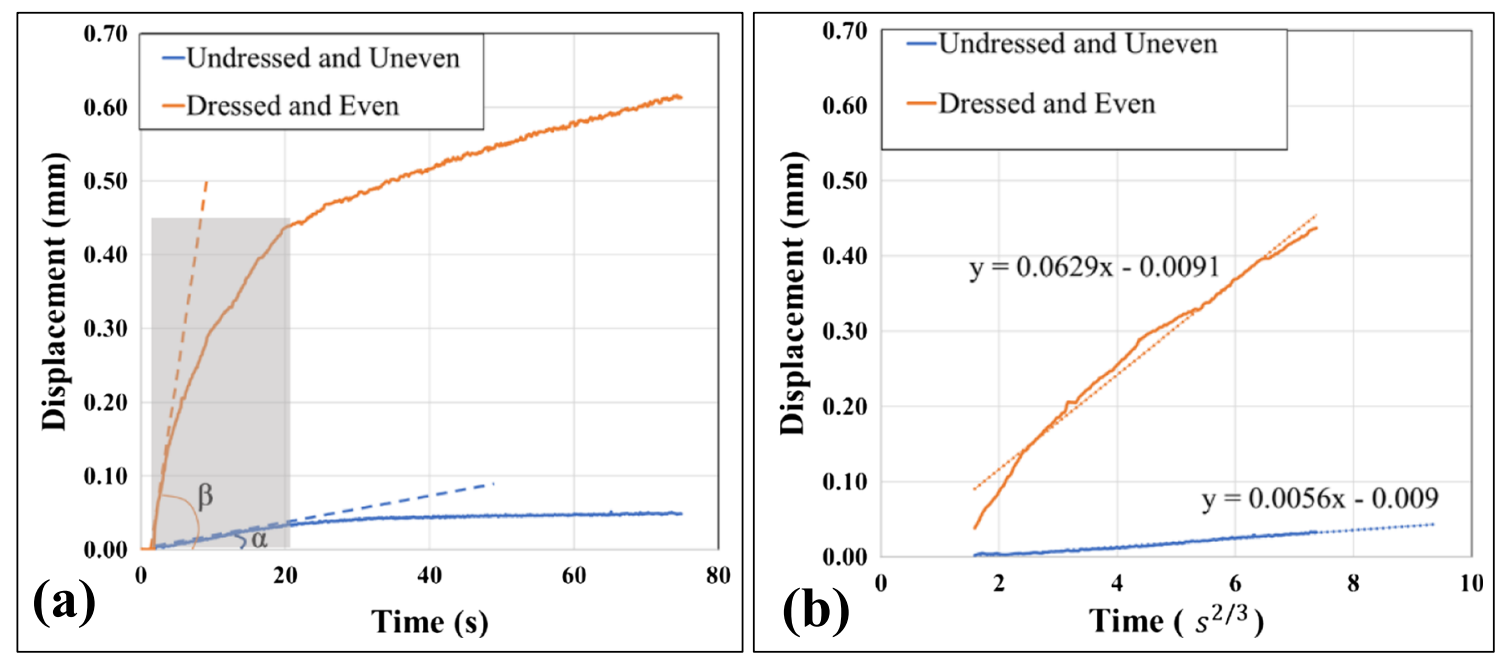

Fig. 6 a Sharpness conditions. b Magnification of the region used to calculate the sharpness 
Table 2 Sharpness parameters

\begin{tabular}{llllc}
\hline Condition & $\begin{array}{l}\alpha \text { and } \beta \text { angles } \\
\left({ }^{\circ}\right)\end{array}$ & $\begin{array}{l}\text { Gradient of the } \\
\text { regression line (a) }\end{array}$ & $\begin{array}{l}\text { Angle after } \\
\text { Transform }\left({ }^{\circ}\right)\end{array}$ & $\begin{array}{l}\text { Sharpness } \\
\left(\mathrm{mm}^{3} / \mathrm{N}^{*} \mathrm{~s}\right)\end{array}$ \\
\hline Undressed and uneven & 0.006 & 0.0056 & 0.32 & 0.569 \\
Dressed and even & 2.65 & 0.0629 & 3.60 & 2.854 \\
\hline
\end{tabular}

without cutting capacity, i.e., not sharp, the capacity to remove material is much lower than that of the full capacity. The grinding wheel surface results in different values of sharpness in such a way that a surface with greater evenness removes a larger quantity of material in the grinding process, since a larger portion of abrasive grains will be in contact with the workpiece. On the other hand, an uneven surface will not achieve the same efficiency in the contact between the grinding wheel surface and the workpiece, producing a surface out of the required specifications, or even causing damages to it.

\subsection{Analysis of the RMS and ROP statistical parameters}

Figure 7a shows the RMS signal for the 1st and 21st dressing passes. Figure $7 \mathrm{~b}$ shows the mean values and the standard deviation of the RMS signals for the test III. Figure 7a shows very small difference between the maximum and minimum RMS values for the wheel not dressed (pass 1) and dressed (pass 21), which is about 34 and $54 \mathrm{mV}$, respectively, and therefore, the same standard deviation behavior is observed. It is possible to observe this behavior more clearly in Fig. 7b, where the variation of the standard deviation is minimal for the RMS signals throughout the dressing process. Such behavior does not characterize the irregularities of the grinding wheel surface, which makes the irregularity detection unfeasible by using these standard deviation values. Therefore, the RMS mean values and the standard deviation values were not considered in this research work.

Figure $8 \mathrm{a}$ shows the characteristic behavior of the ROP statistic for three conditions of the grinding wheel, i.e., undressed and uneven (a), dressed and uneven (b), and dressed and even (c). It can be observed in this figure that a worn grinding wheel has on its surface numerous peaks and valleys that influence directly on the AE signal. Due to the unevenness of the grinding wheel during the dressing time, the contact of the dresser with the grinding wheel does not occur on a regular basis, causing several events in the AE signals, such as
Fig. 7 a RMS pass 1 and RMS pass 21. b Mean values and standard deviation of the RMS signal for test III

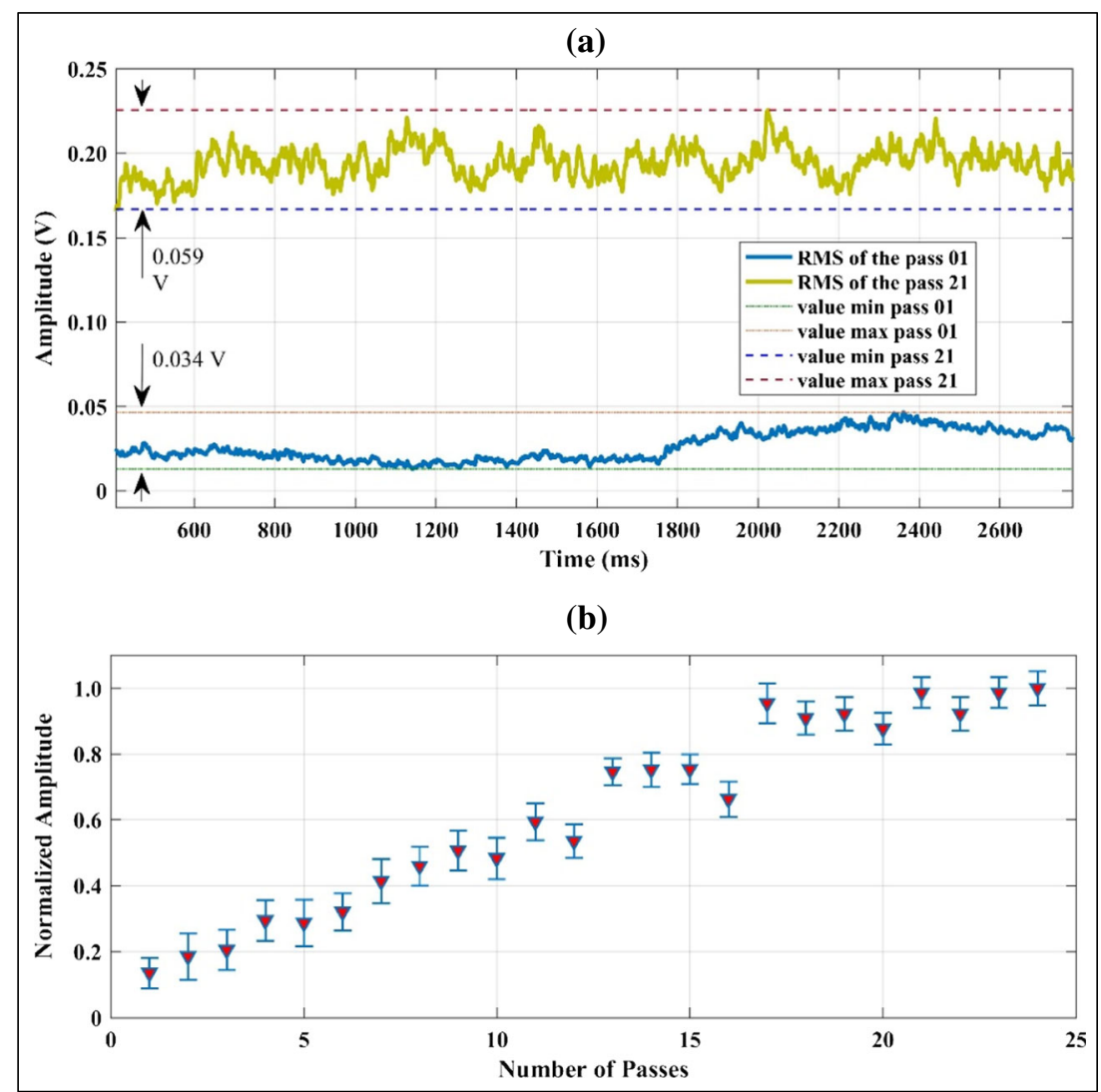




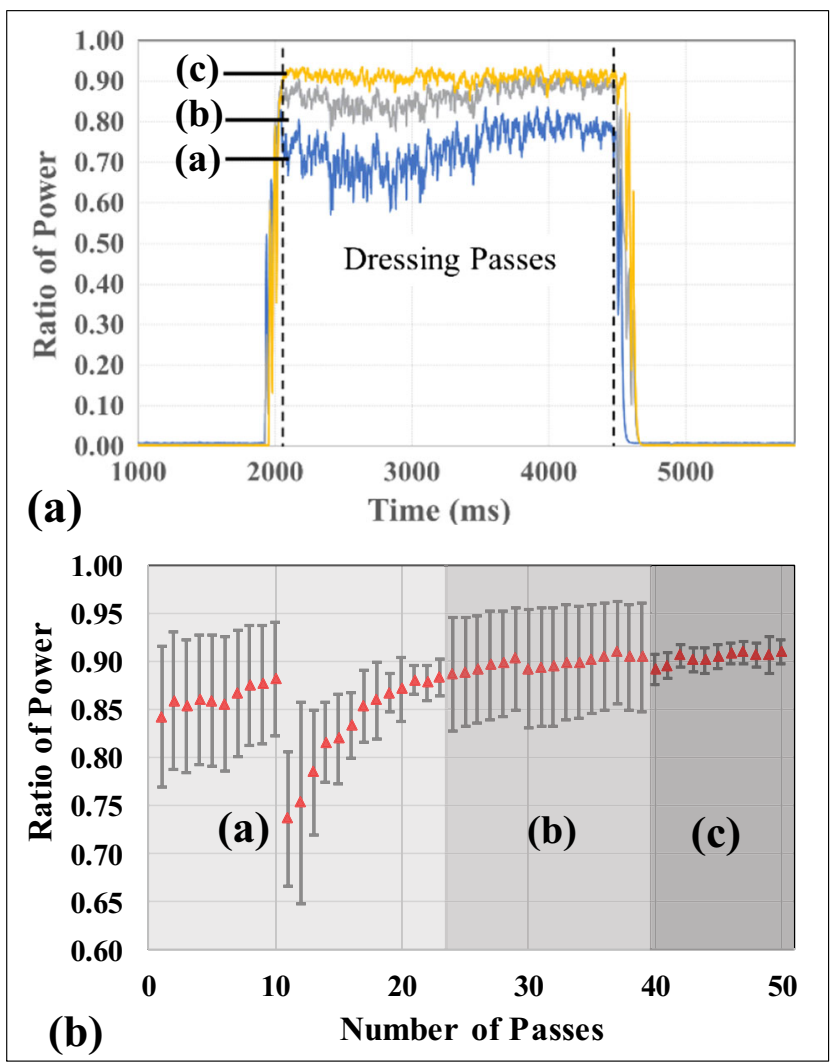

Fig. 8 ROP for four conditions of grinding wheel (a) and input vector of the fuzzy model (b)

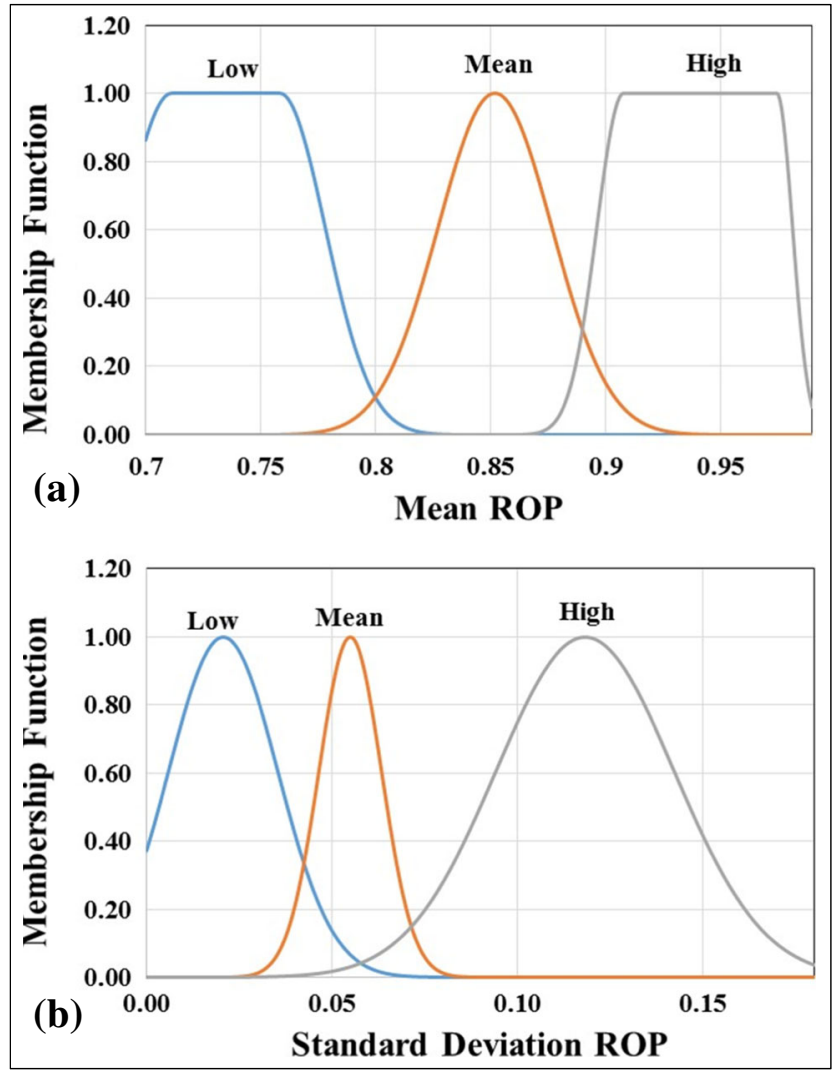

Fig. 9 Input membership functions. a Mean ROP. b Standard deviation ROP high deviations, discontinuities, and transients. Figure $8 \mathrm{~b}$ shows the ROP mean values and their respective standard deviations. It is observed in the region (a) of Fig. $8 \mathrm{~b}$ that ROP amplitudes are smaller than the other regions, which means a grinding wheel with clogged surface, i.e., impregnated with chips, and consequently a less intense acoustic activity, as reported in [11].

It is also observed a large standard deviation of ROP in this region, which implies great unevenness of the grinding wheel surface due to the partial contact of the dresser with the surface of the grinding wheel during the dressing process. It is also observed a high standard deviation in Fig. 8b, but with higher amplitudes than in region (a), indicating that the surface of the grinding wheel is dressed in part of grinding wheel and uneven in the remaining part. Finally, the region (c) has the highest amplitude and lowest standard deviations of the ROP statistic, because the dresser makes full contact with the surface of the grinding wheel in this dressed and even condition, which is cleaned and conditioned.

\subsection{Discussions on the fuzzy model}

The behavior of the ROP statistic compared to the condition of the grinding wheel surface, shown in Fig. 8b, is completely nonlinear, indicating a difficult diagnosis. The input vector was constructed from the mean values of the amplitudes and the standard deviations of the statistic of every dressing pass. Figure 9 shows two sets of input membership functions. From the input data shown in Fig. 8b, three distinct regions were identified. Thus, from the mean values, three linguistic variables were adopted and named as low, medium, and high. The low, medium, and high linguistic values represent the grinding wheel without cutting capacity, with intermediate cutting capacity and with full cutting capacity, respectively. The low, medium, and high linguistic variables of the standard deviation represent the uneven grinding wheel, with intermediate evenness, and smooth surface, respectively. The quantity of membership functions is related to the complexity of the

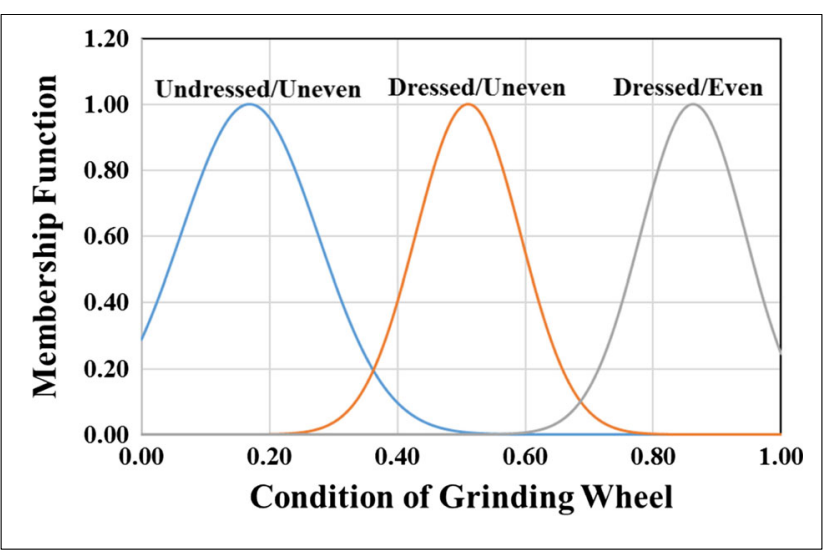

Fig. 10 Output membership functions 
Table 3 Set of rules

ROP mean 25-40 kHz

ROP standard deviation $25-40 \mathrm{kHz}$

\begin{tabular}{llll} 
& Low & Mean & High \\
Low & Undressed/uneven surface & Undressed/uneven Surface & Dressed/even Surface \\
Mean & Undressed/uneven surface & Undressed/uneven Surface & Dressed/uneven surface \\
High & Undressed/uneven surface & Undressed/uneven Surface & Dressed/uneven surface \\
\hline
\end{tabular}

system. In view of the complexity and the effectiveness of the system associated with the knowledge of the group of experts, only three membership functions were necessary.

This use of just three membership functions is justified because other fuzzy controllers with more membership functions have been tested, which increased the complexity of the system without significant improvement in the final result.

Figure 10 shows the single set of output functions. The Gaussian membership functions were chosen due to the smooth transition and better behavior in situations of sudden transient. The same criterion applied to the inputs shown in Fig. 9 was also applied to the output membership functions of the fuzzy system, i.e., a minimal amount of membership functions was used, which satisfactorily characterizes the requirements of shape and sharpness of the grinding wheel.

Based on the fuzzified inputs and outputs, an inference system was established for a fuzzy model. The choice of inputs (ROP mean values and standard deviation) is based on the characterization of the process.

The relationship among the inputs contains, at the same time, the conditions of the cutting tool regarding its shape (even and uneven) and its sharpness (dressed and undressed).

The set of rules extracted for the model was obtained from the input data of the signal (ROP mean values and ROP standard deviation), as well as the experience of the research group involved (specialists), thus characterizing a typical fuzzy system. Table 3 presents the set of rules for the proposed fuzzy controller.

Based on the set of rules previously obtained for the fuzzy model and inserted into Matalab®, a 3D surface was

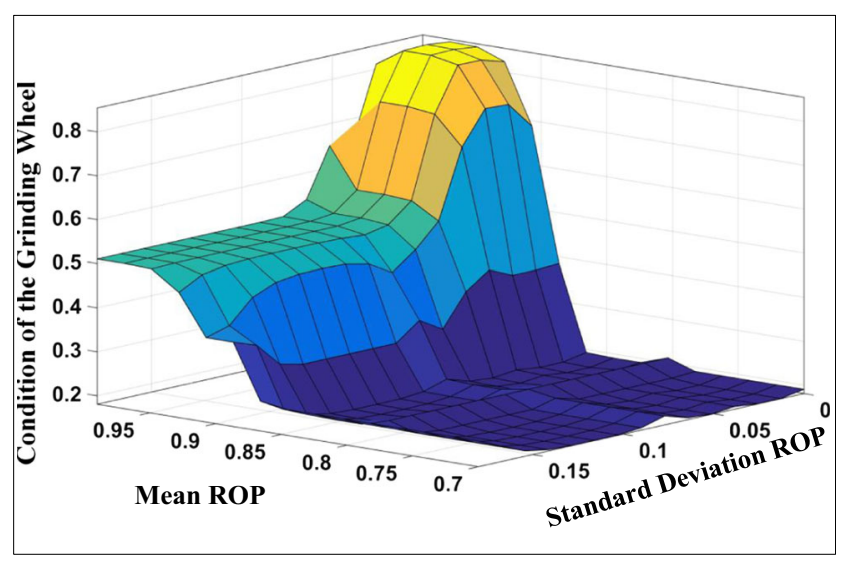

Fig. 11 3D surface- fuzzy controller generated, as shown in Fig. 11, to observe the input and output effects of the fuzzy model. The smoothness in the transitions from one condition of the grinding wheel to another is the main feature of this 3D surface, in addition to showing welldefined areas in relation to the set of rules.

The combined inputs resulted in different influences on predicting the life span of the cutting tool (grinding wheel). According to the rules surface, when the mean has a high value and the standard deviation has a low value, the grinding wheel reaches its best condition, about 0.84 , i.e., dressed and even. However, if the standard deviation is high and the mean is low, the condition obtained is represented by 0.17 , which indicates a bad condition of the grinding wheel (bad shape and sharpness), i.e., undressed and uneven. The intermediate condition regarding the dressed and uneven wheel is related to the means and standard deviations in intermediate levels. Figure 12 shows an example for two input vectors.

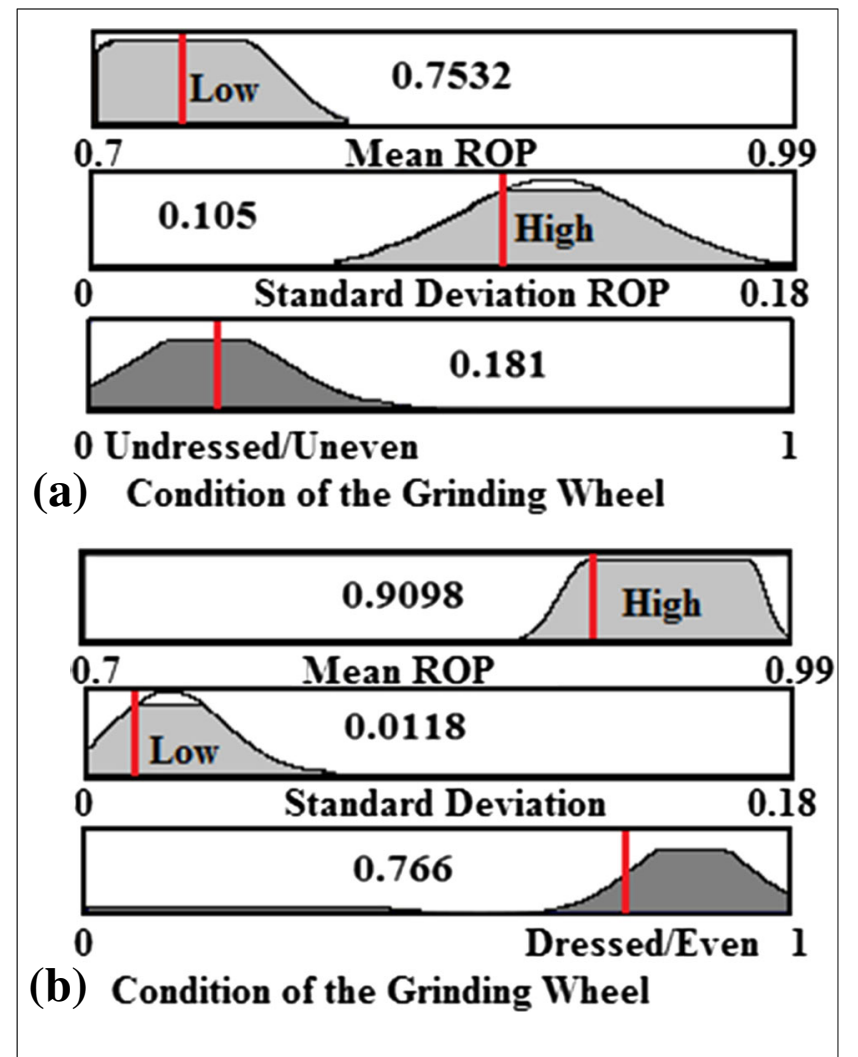

Fig. 12 Example of membership functions. a Dressed and even conditions. b Undressed and uneven conditions 


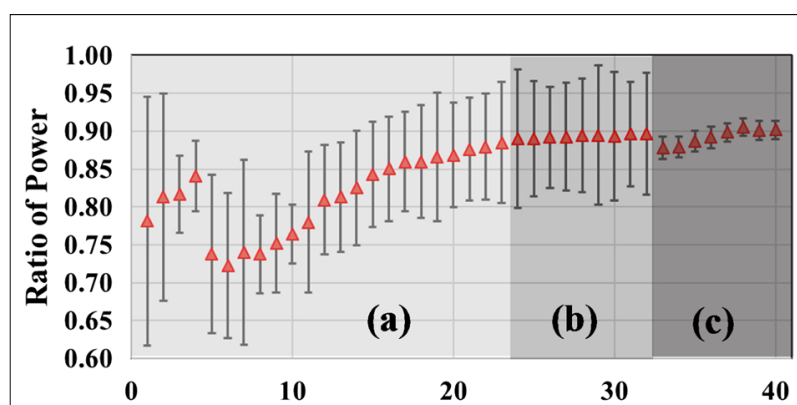

(a) Number of Passes

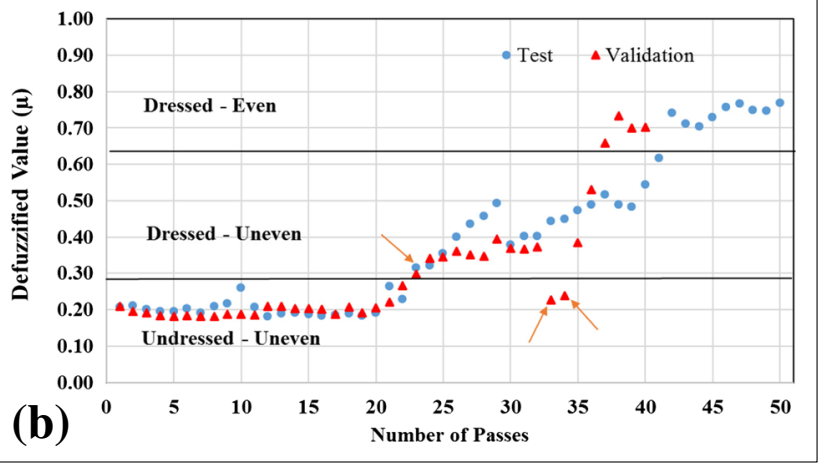

Fig. 13 Validation results (a) and response (b) of the fuzzy controller

Figure 12a shows the result of the fuzzy system for an input of mean value of 0.7532 and standard deviation of 0.105 . The membership function enabled is equivalent to the undressed and uneven wheel, because the mean is low and the standard deviation is high. On the other hand, Fig. 12b shows the result for the mean value of 0.9098 and standard deviation of 0.0118 , which leads to the activation of the membership function regarding the dressed and even grinding wheel, since the mean is high and the standard deviation is low.

To validate the fuzzy controller, a matrix consisting of mean values and standard deviations of the ROP statistic, from tests IV and V, was used. It is worth mentioning that the computation of ROP statistic was based on the selected frequency band of $25-40 \mathrm{kHz}$. The matrix has three distinct regions as shown in Fig. 13a. The region (a) represents the undressed and uneven condition, the region (b) represents the dressed and uneven condition, and finally, the region (c) represents the dressed and even condition. Figure 13b shows the response of the fuzzy controller. The result indicates consistency in about $92 \%$ of the samples. The samples of numbers 33 and 34 presented low standard deviation and low mean values, indicating a condition that is not represented by the controller. This condition occurs due to some variations throughout the dressing process, such as the emergence of new cutting edges and uneven wear of the dresser diamond. Therefore, the fuzzy controller indicates robustness in view of the results and high assertiveness, which is essential in practical applications.

\section{Conclusions}

This work presented a method to evaluate the conditions of the cutting tool (grinding wheel) with respect to their surface regularities and dressing condition based on the study of the frequency content of AE signals. The frequency band of $25-40 \mathrm{kHz}$ best characterized three grinding wheel conditions studied. The RMS and ROP statistics of the signals were calculated to extract relevant features related to the grinding wheel conditions. However, the RMS statistic did not show a consistent behavior regarding the surface irregularities of the grinding wheel and then discarded. A fuzzy model was developed to indicate the condition of the grinding wheel surface. The mean value and the standard deviation of the ROP statistic were computed for each pass considering the selected frequency band. The fuzzy model was implemented in Matlab ${ }^{\circledR}$, which consisted of the mean values and standard deviations of ROP as inputs. The fuzzy model showed high assertiveness, even though the data have strongly shown non-linear behavior. Due to its simplicity, the fuzzy model can be attractive for manufacturing industry, engineers and technicians responsible for the grinding and dressing operation.

Such findings are only applied for the tools used in this study (aluminum oxide grinding wheel and single-point CVD dresser). As a suggestion for future works, it is expected to generalize the model to other types of dressers and increase the number of inputs to allow the system to become more robust, as well as including other characteristics that could be obtained during the dressing operation. Thus, other experiments should be performed, and the use of different statistic parameters may also be used to characterize the dressing operation, e.g., the counts statistic used in [12].

Acknowledgements Thanks go to the Norton Company for the grinding wheel donation.

Funding information The authors would like to thank the Brazilian research agencies National Council for Scientific and Technological Development $(\mathrm{CNPq})$ and Coordination for the Improvement of Higher Education Personnel (CAPES) for funding this work.

\section{References}

1. Jiang JL, Ge PQ, Bi WB, Zhang L, Wang DX, Zhang Y (2013) 2D/ $3 \mathrm{D}$ ground surface topography modeling considering dressing and wear effects in grinding process. Int J Mach Tools Manuf 74:29-40. https://doi.org/10.1016/j.ijmachtools.2013.07.002

2. Winter M, Li W, Kara S, Herrmann C (2014) Determining optimal process parameters to increase the eco-efficiency of grinding processes. J Clean Prod 66:644-654. https://doi.org/10.1016/j.jclepro. 2013.10.031

3. Kalpakjian S, Schmid SR (2014) Manufacturing Engineering and Technology, 7th ed, Pearson Education South Asia Pte Ltd, Singapore 
4. Hadad M, Sharbati A (2016) Analysis of the effects of dressing and wheel topography on grinding process under different coolantlubricant conditions. Int J Adv Manuf Technol 90(9-12):37273738. https://doi.org/10.1007/s00170-016-9703-0

5. Liu Y, Warkentin A, Bauer R, Gong Y (2013) Investigation of different grain shapes and dressing to predict surface roughness in grinding using kinematic simulations. Precis Eng 37(3):758-764. https://doi.org/10.1016/j.precisioneng.2013.02.009

6. De Pellegrin DV, Stachowiak GW (2004) Sharpness of abrasive particles and surfaces. Wear 256(6):614-622. https://doi.org/10. 1016/j.wear.2003.10.004

7. Torrance AA, Badger JA (2000) Relation between the traverse dressing of vitrified grinding wheels and their performance. Int $\mathrm{J}$ Mach Tools Manuf 40(12):1787-1811. https://doi.org/10.1016/ S0890-6955(00)00015-8

8. Martins CHR, Aguiar PR, Frech A, Bianchi EC (2014) Tool condition monitoring of single-point dresser using acoustic emission and neural networks models. IEEE Trans Instrum Meas 63(3):667679. https://doi.org/10.1109/TIM.2013.2281576

9. Zhou JH, Pang CK, Zhong ZW, Lewis FL (2011) Tool wear monitoring using acoustic emissions by dominant-feature identification. IEEE Trans Instrum Meas 60(2):547-559. https://doi.org/10.1109/ TIM.2010.2050974

10. Mishra BK, Yadav B, Jha SK, Burnwal AP (2015) Fuzzy set theory approch to model super abrasive grinding process using weighted compensatory operator. Int J Res Comput Appl Robot - IJRCAR 3: $62-68$

11. Moia DFG, Thomazella IH, Aguiar PR, Bianchi EC, Martins CHR, Marchi M (2015) Tool condition monitoring of aluminum oxide grinding wheel in dressing operation using acoustic emission and neural networks. J Braz Soc Mech Sci Eng 37(2):627-640. https:// doi.org/10.1007/s40430-014-0191-6

12. Lopes WN, Ferreira FI, Alexandre F et al (2017) Digital signal processing of acoustic emission signals using power spectral density and counts statistic applied to single-point dressing operation. IET Sci Meas Technol 15(5):631-636. https://doi.org/10.1049/ietsmt.2016.0317

13. Dutta S, Pal SK, Mukhopadhyay S, Sen R (2013) Application of digital image processing in tool condition monitoring: a review. CIRP J Manuf Sci Technol 6(3):212-232. https://doi.org/10.1016/ j.cirpj.2013.02.005

14. D'Addona DM, Matarazzo D, De Aguiar PR et al (2016) Neural networks tool condition monitoring in single-point dressing operations. Procedia CIRP 41:431-436. https://doi.org/10.1016/j.procir. 2016.01.001

15. Cearsolo X, Cabanes I, Sanchez JA et al (2016) Dry-dressing for ecological grinding. J Clean Prod 135:633-643. https://doi.org/10. 1016/j.jclepro.2016.06.117

16. Rascalha A, Brandão LC, Filho SLMR (2013) Optimization of the dressing operation using load cells and the Taguchi method in the centerless grinding process. Int J Adv Manuf Technol 67(5-8): 1103-1112. https://doi.org/10.1007/s00170-012-4551-z

17. Nakayama K, Takagi J, Etsuo I, Okuno K (1980) Sharpness evaluation of grinding wheel face by the grinding of steel ball. Ann CIRP 29(1):227-231. https://doi.org/10.1016/S0007-8506(07)61327-4

18. Coelho RT (1991) Experimental study on the dressing depth of grinding wheels in precision grinding using the ground disc method. University of Sao Paulo, Sao Carlos

19. Martins CHR, Aguiar PR, Frech A, Bianchi EC (2013) Neural networks models for wear patterns recognition of single-point dresser. IFAC Proc 46:1524-1529. https://doi.org/10.3182/ 20130619-3-RU-3018.00222

20. Miranda HI, Rocha CA, Oliveira P et al (2015) Monitoring singlepoint dressers using fuzzy models. Procedia CIRP 33:281-286. https://doi.org/10.1016/j.procir.2015.06.050

21. Agarwal S (2015) Optimizing machining parameters to combine high productivity with high surface integrity in grinding silicon carbide ceramics. Ceram Int 42(5):6244-6262. https://doi.org/10. 1016/j.ceramint.2016.01.008

22. Azadegan A, Porobic L, Ghazinoory S, Samouei P, Saman Kheirkhah A (2011) Fuzzy logic in manufacturing: a review of literature and a specialized application. Int J Prod Econ 132(2): 258-270. https://doi.org/10.1016/j.ijpe.2011.04.018

23. Mohd Adnan MRH, Sarkheyli A, Mohd Zain A, Haron H (2013) Fuzzy logic for modeling machining process: a review. Artif Intell Rev 43:345-379. https://doi.org/10.1007/s10462-012-9381-8

24. Virivinti N, Mitra K (2014) Fuzzy expected value analysis of an industrial grinding process. Powder Technol 268:9-18. https://doi. org/10.1016/j.powtec.2014.08.001

25. Liu SX, Tong F, Luk BL, Liu KP (2011) Fuzzy pattern recognition of impact acoustic signals for nondestructive evaluation. Sensors Actuators A Phys 167(2):588-593. https://doi.org/10.1016/j.sna. 2011.03.015

26. Kor M, Abkhoshk E, Tao D, Chen GL, Modarres H (2010) Modeling and optimization of high chromium alloy wear in phosphate laboratory grinding mill with fuzzy logic and particle swarm optimization technique. Miner Eng 23(9):713-719. https://doi.org/ 10.1016/j.mineng.2010.04.009

27. Kaya M, Alhajj R (2003) A clustering algorithm with genetically optimized membership functions for fuzzy association rules mining. In: The 12th IEEE International Conference on Fuzzy Systems, FUZZ '03. IEEE, pp 881-886

28. Gill SS, Singh J (2010) An adaptive neuro-fuzzy inference system modeling for material removal rate in stationary ultrasonic drilling of sillimanite ceramic. Expert Syst Appl 37(8):5590-5598. https:// doi.org/10.1016/j.eswa.2010.02.054

29. Precup RE, Hellendoorn H (2011) A survey on industrial applications of fuzzy control. Comput Ind 62(3):213-226. https://doi.org/ 10.1016/j.compind.2010.10.001

30. De Oliveira JFG, De Purquerio BM, Coelho RT, Bianchi EC (1992) Grinding process dominance by means of the dressing operation. In: Proceedings of the Twenty-Ninth International Matador Conference. Macmillan Education UK, London, pp 547-550. https://doi.org/10.1007/978-1-349-12433-6_72

31. Miranda HIC, Aguiar PR, Euzebio CDG, Bianchi EC (2010) Fuzzy Logic to Predict Thermal Damages of Ground Parts. In: Artificial Intelligence and Applications. ACTAPRESS, Calgary, AB, Canada, pp 434-441. https://doi.org/10.2316/P.2010.674-116

32. Ribeiro DMS, Aguiar PR, Fabiano LFG, D'Addona DM, Baptista FG, Bianchi EC (2017) Spectra measurements using piezoelectric diaphragms to detect burn in grinding process. IEEE Trans Instrum Meas 66(11):3052-3063. https://doi.org/10.1109/TIM.2017. 2731038

33. Webster J, Dong WP, Lindsay R (1996) Raw acoustic emission signal analysis of grinding process. CIRP Ann-Manuf Technol 45(1):335-340. https://doi.org/10.1016/S0007-8506(07)63075-3

34. Euzébio CDG, Aguiar PR, Miranda HIC, Bianchi EC (2012) Monitoring of grinding burn by fuzzy logic. ABCM Symp Ser Mechatronics - Vol 5 5:637-645. https://doi.org/10.5772/2070 